\title{
Mosaicism for combined tetrasomy of chromosomes 8 and 18 in a dysmorphic child: A result of failed tetraploidy correction? Gunnar Houge ${ }^{* 1,2}$, Helle Lybæk ${ }^{1}$ and Sasha Gulati ${ }^{3}$
} Address: ${ }^{1}$ Center for Medical Genetics and Molecular Medicine, Haukeland University Hospital, Bergen, Norway, ${ }^{2}$ Department of Clinical
Medicine, University of Bergen, Bergan, Norway and ${ }^{3}$ Department of Pediatrics, Ålesund Hospital, Ålesund, Norway

Email: Gunnar Houge* - gunnar.houge@helse-bergen.no; Helle Lybæk - helle.lybak@helse-bergen.no; Sasha Gulati - sashagulati@hotmail.com

* Corresponding author

Published: 18 May 2009

BMC Medical Genetics 2009, 10:42 doi:10.1 186/147I-2350-10-42
Received: 3 October 2008

Accepted: 18 May 2009

This article is available from: http://www.biomedcentral.com/I47I-2350/I0/42

(C) 2009 Houge et al; licensee BioMed Central Ltd.

This is an Open Access article distributed under the terms of the Creative Commons Attribution License (http://creativecommons.org/licenses/by/2.0), which permits unrestricted use, distribution, and reproduction in any medium, provided the original work is properly cited.

\begin{abstract}
Background: Mosaic whole-chromosome tetrasomy has not previously been described as a cause of fetal malformations.

Case presentation: In a markedly dysmorphic child with heart malformations and developmental delay, CGH analysis of newborn blood DNA suggested a 50\% dose increase of chromosomes 8 and 18, despite a normal standard karyotype investigation. Subsequent FISH analysis revealed leukocytes with four chromosomes 8 and four chromosomes 18. The child's phenotype had resemblance to both mosaic trisomy 8 and mosaic trisomy 18 . The double tetrasomy was caused by mitotic malsegregation of all four chromatids of both chromosome pairs. A possible origin of such an error is incomplete correction of a tetraploid state resulting from failed cytokinesis or mitotic slippage during early embryonic development.
\end{abstract}

Conclusion: This unique case suggests that embryonic cells may have a mechanism for tetraploidy correction that involves mitotic pairing of homologous chromosomes.

\section{Background}

Unlike meiotic non-disjunctions, mitotic non-disjunctions are rarely observed in humans with the exception of mosaicism for trisomy 8,9 or 20 [1,2]. In some cases mosaic trisomy of more than one chromosome have been seen [3]. Such mosaic variegated aneuploidy is due to mitotic errors, often associated with premature centromere division [4]. In contrast to mosaic trisomies, the finding of mosaic whole-chromosome tetrasomy is without precedence. Here we present such a patient; a dysmorphic newborn child with mosaicism of leukocytes containing 50 chromosomes due to tetrasomy of chromosomes 8 and 18 . This unique clinical case may have relevance concerning the origin of aneuploidy in cancer [5-8] because it indirectly suggests that there might be a mech- anism for tetraploidy correction during fetal development that involves mitotic pairing of homologous chromosomes.

\section{Case presentation}

A baby girl was delivered by cesarean section in week 36 due to maternal hypertension with mild preeclampsia, birth weight $2910 \mathrm{~g}$, length $47 \mathrm{~cm}$. Polyhydramnios was detected at the end of the pregnancy. She had persistent ductus arteriosus (PDA), a small muscular-type ventricle septal defect (VSD) and coarctation of the aorta. The coarctatio aortae was resected at age 6 weeks, and at the same time the PDA was ligated. She has always been short statured: At age 4 months her length was $57 \mathrm{~cm}(1 \mathrm{~cm}$ below $2.5^{\text {th }}$ centile), at age $21 / 2$ years $81 \mathrm{~cm}(4 \mathrm{~cm}$ below 
$2.5^{\text {th }}$ centile). Head circumferences were about $1 \mathrm{~cm}$ below the $2.5^{\text {th }}$ centile, e.g. $46 \mathrm{~cm}$ at age $21 / 2$ years. Major feeding difficulties necessitated gastrostomy at age 4 months. At current age ( 2 years and 10 months) she still has no interest for food and vomits easily, but feeding her through the enteral feeding tube (Mic-Key ${ }^{\circledR}$ ) keeps her weight within normal range. On barium-contrast X-ray examination of the esophagus, peristalsis appeared normal without signs of gastro-esophageal reflux. A 24-hour esophageal pH-measurement also gave no indications of reflux. There has been clear psychomotor delay: She started to walk without support at age 2 years and has delayed language development, e.g. at age 21 /2 years she spoke only $8-10$ words but managed quite well by sign language. On neurological examination mirror movements of her hands were found. She also has hearing loss, already suspected before age 2 months and confirmed by brain stem audiometry at age 4 months. On CT-examination of the temporal bone, atretic auditory canals and no middle ear cavities were found. There is marked facial dysmorphism with high frontal hairline, low-set and posteriorly rotated small ears with crumpled helices, inverted epicanthus, short and down-slanting palpebral fissures, no visible eyelashes on lower eyelids, broad nasal root, thin upper lip, small chin and a short neck (Figure 1). A transverse palmar crease was found in the right hand, and on the inside of the left thigh brownish longitudinal streaks were seen. The right foot was deformed with the $1^{\text {st }}$ toe bent in under the $2^{\text {nd }}$ toe (Figure 1$)$. On ophthalmological examination in narcosis, the optic papillae were grayish, and there were some granulations of the retinae in the macular areas. At present, she is an active girl that likes to play. Her only medication is for asthma.

\section{Results and Discussion}

Because the girl was dysmorphic with major feeding difficulties, blood samples were drawn two days after birth for chromosome investigations; routine G-banding and chromosome-based high-resolution comparative genomic hybridization (HR-CGH). The G-banded karyotype, based on screening of ten metaphases from a phytohemagglutinin-stimulated 3-day blood lymphocyte cultures, was normal. Surprisingly, the HR-CGH result that came a few weeks later suggested a combination of non-mosaic trisomy 8 and trisomy 18 (Figure 2, panel A). An identical finding was subsequently done on a 3500 BAC-clone array-CGH platform made by the Norwegian Microarray Consortium (for details, see [9]), the ratio still indicating a 50\% increase in DNA amount corresponding to chromosomes 8 and 18 (Figure 2, panel B). To investigate if uniparental disomy of other chromosomes might be present, or if abnormal copy number variants below the resolution limit of the 3500 BAC-clone array might be found, we have recently examined DNA from the child's
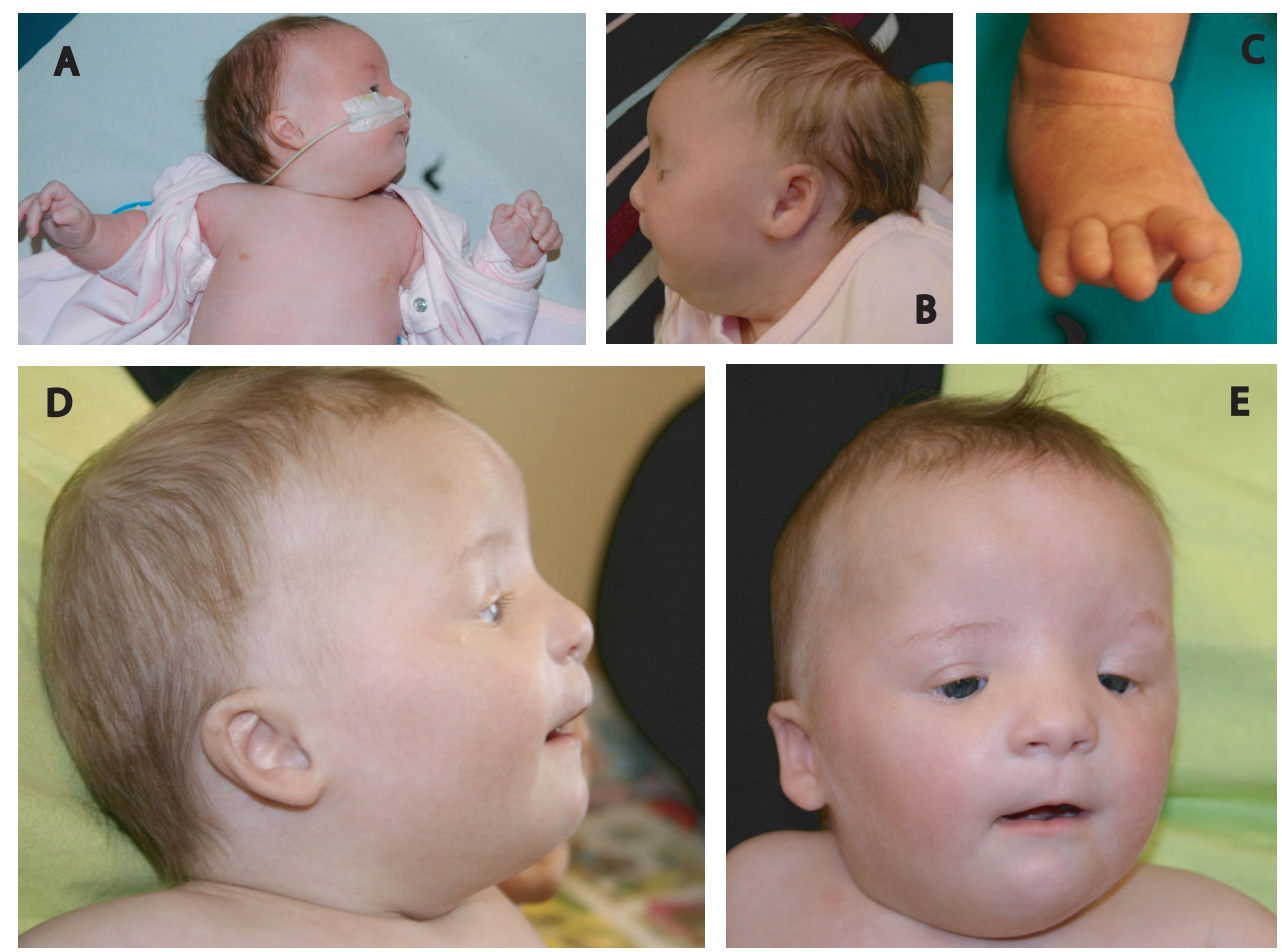

\section{Figure I}

The child with double tetrasomy $8+18$ mosaicism at age 7 weeks (panels A-C) and age I year (panels D-E). 
A
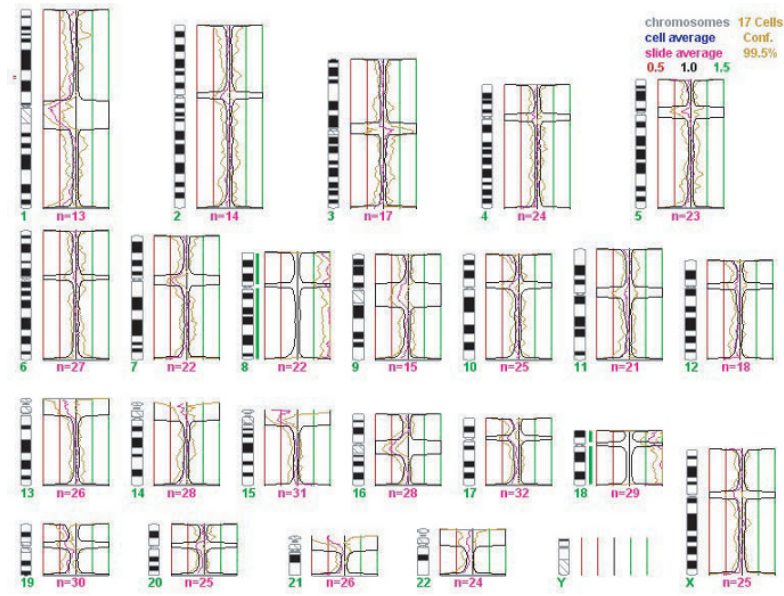

B

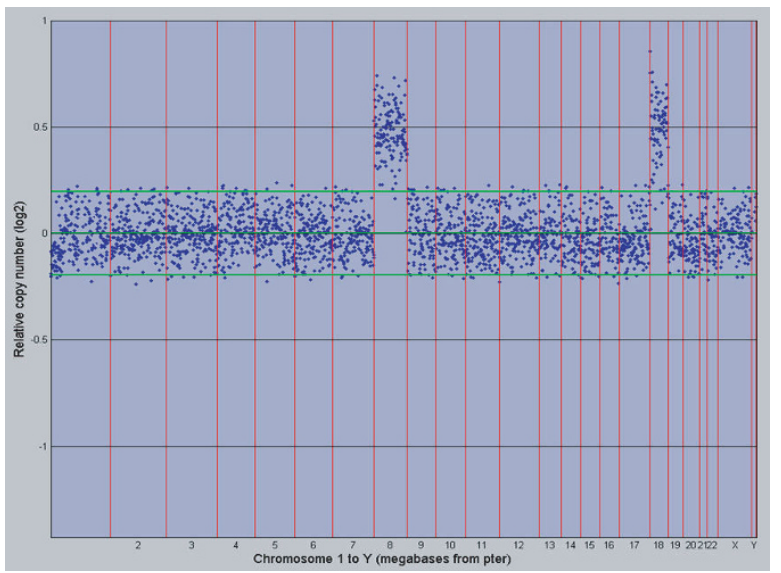

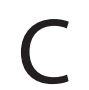

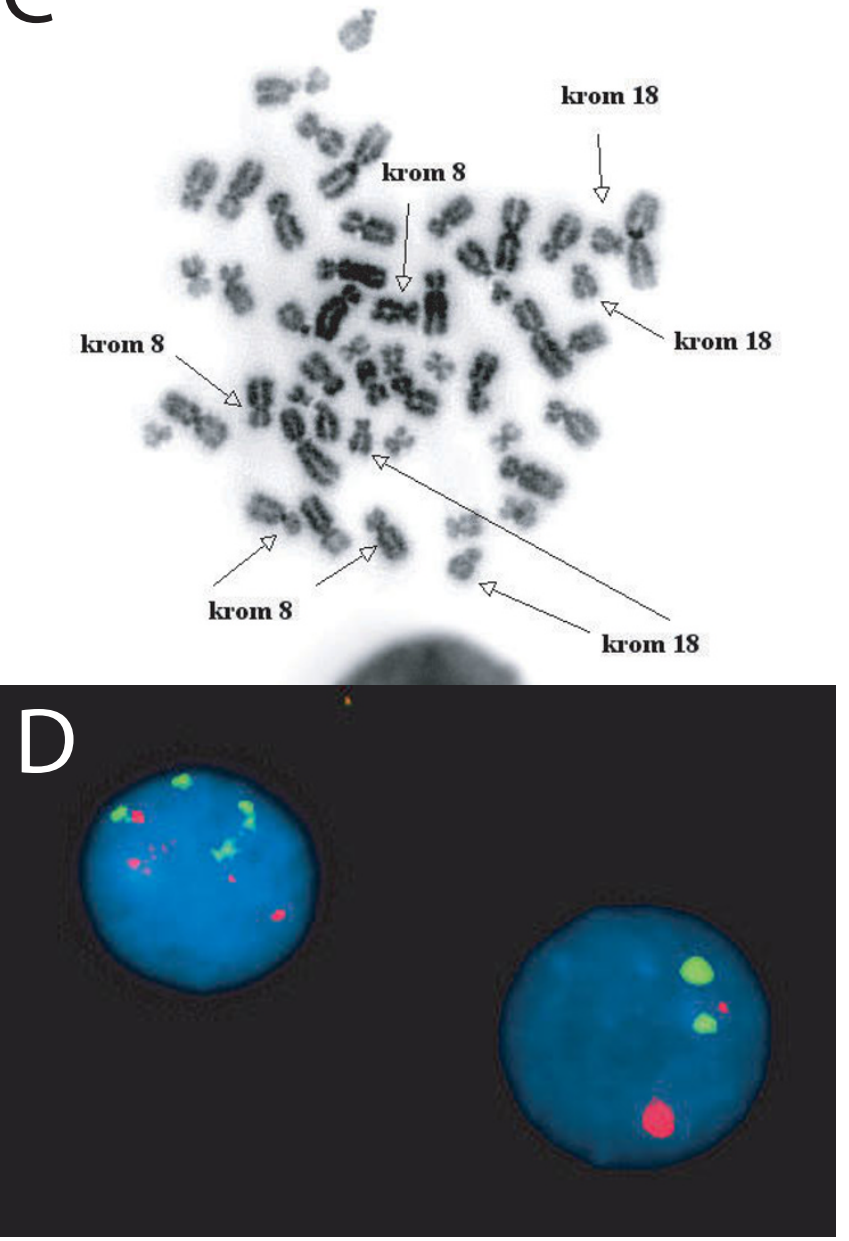

Figure 2

Chromosome-based high-resolution CGH result (panel A) and I Mb BAC-array CGH result (panel B) on a blood DNA sample collected at age two days. The apparent 50\% increase in DNA amount corresponding to chromosomes 8 and 18 was due to double tetrasomy of both chromosomes (panel C, showing a double tetrasomic metaphase). By interphase FISH, four copies of chromosomes 8 and 18 were detected in $15 \%$ of the cells from a 3-days PHA-stimulated blood culture (panel D).

original blood sample (taken at age 2 days) on the Affymetrix Genome-Wide Human SNP Assay Kit version 6.0 (Affymetrix, Inc., CA). No indication of uniparental disomy (i.e. larger regions of homozygocity) was found, and no additional (and structural) de novo copy number abnormalities were detected.

A re-examination of the original leukocyte cell culture suspension with FISH-probes for centromeres 8 and 18 explained the surprising CGH finding: In $2 \%$ of the metaphases (100 metaphases examined) and $15 \%$ of the interphases (200 nuclei examined) tetrasomy for both chromosomes were found (Figure 2, panels $\mathrm{C}$ and D). The discrepancy between the CGH-findings $(50 \%$ dose increase for 8 and 18 , suggesting that $50 \%$ of the cells had four chromosomes 8 and 18) and the cell culture findings (15\% of the interphases had four chromosomes 8 and 18 ) were likely due to negative selection of double tetrasomic cells during PHA-stimulated culturing of blood leukocytes. This illustrates that conventional G-banded karyotyping may easily overlook such mosaicism. To investigate other tissues for similar mosaicism, a skin biopsy from the inside of the left thigh was collected for fibroblast culturing at age 4 months, and at age 14 months a buccal smear was collected. In none of these tissues double tetrasomic cells were found by interphase centromere $8+18$ FISH with 200 nuclei examined in each case. At age 20 months, a new blood sample was taken, and the double tetrasomic cells could no longer be detected, neither by CGH nor by interphase FISH. 
To determine the origin of the four extra chromosomes (two chromosomes 8 and two chromosomes 18) that probably were present in around 50\% of the blood leukocytes at the time of birth, microsatellite markers for chromosomes 8 and 18 were compared between blood-DNA samples from the parents and the original child bloodDNA sample taken at age 2 days (Table 1 ). There was no indication of more than two alleles for any simple tandem repeat examined, making meiotic non-disjunction an unlikely mechanism. Furthermore, there was no systematic skewing of the ratios between maternal and paternal allele peak sizes (Table 1), which would have been the case if three of the chromosomes in each quadruple were uniparental. Taken together, this indicates that the mosaicism was a consequence of mitotic events, and that the origin is a mitotic division where all four chromatids of two chromosome pairs ( 8 and 18) segregated to one daughter cell only.

The finding of tetrasomy for two autosomes in a newborn is without precedence. To the best of our knowledge, even single chromosome tetrasomy mosaicism has not previously been reported - except in cancer cells. The reason for the uniqueness of our finding is either that this indeed is a very rare chromosomal aberration, or that this type of malsegregation commonly occurs but is not detected due to negative selection against aneuploid cells during embryonic development and the culturing of blood cells for routine karyotyping. We were fortunate to observe this because we performed "unbiased" CGH analyses on leukocyte DNA from a newborn. Moreover, extra copies of both of the involved chromosomes are known to be compatible with sustained cell growth in the embryo, increasing the likelihood that a double tetrasomic cell line could survive to term. Notably, the initial cytogenetic investigation (G-banding) appeared normal - only a later reexamination by FISH revealed double tetrasomic cells and metaphases (Figure 2). Apparently, the short-term PHAstimulated leukocyte culture decreased the number of aberrant cells from around $50 \%$ to $15 \%$. Twenty months later the aberrant clone was undetectable in blood, probably because it was counter-selected in the bone marrow.

At a later time point we were unsuccessful in finding double tetrasomic cells in other tissues, i.e. in squamous epithelial cells from a buccal smear and cultivated fibroblasts

Table I: Allele sizes of polymorphic chromosome 8 and I 8 simple tandem repeats.

\begin{tabular}{|c|c|c|c|c|c|}
\hline UniSTS & Position (Mb from pter) & Mother (m) & Father $(p)$ & Child & Ratio m/p peak heights \\
\hline \multicolumn{6}{|l|}{ Chrom. 8: } \\
\hline D8S264 & 21 & $153-155$ & $143-153$ & $143-155$ & 0,50 \\
\hline D8SII04 & 41 & $135-135$ & $|43-| 43$ & $135-143$ & $1,0 \mid$ \\
\hline D8S268 & 41 & $260-266$ & $264-266$ & $260-264$ & 1,24 \\
\hline D8S53I & 49 & $121-127$ & $123-123$ & $121-123$ & 1,60 \\
\hline G087I8 & 49 & $219-219$ & $2|4-2| 4$ & $214-219$ & 0,94 \\
\hline D8S5I7 & 53 & $25 I-253$ & $255-258$ & $25 \mathrm{I}-255$ & 1,37 \\
\hline D8S260 & 62 & $207-215$ & $209-215$ & $207-215$ & 1,05 \\
\hline D8S277 & 65 & $165-173$ & $165-169$ & $169-173$ & 1,18 \\
\hline D8S270 & 93 & $101-112$ & $110-112$ & $101-110$ & 1,84 \\
\hline D8SI784 & 106 & $288-288$ & $282-286$ & $282-288$ & 0,71 \\
\hline \multirow[t]{2}{*}{ D8S550 } & 109 & $194-212$ & $210-210$ & $210-212$ & 0,65 \\
\hline & & & & & Mean I,03 \\
\hline \multicolumn{6}{|c|}{ Chrom. 18: } \\
\hline DI8S452 & 6 & $128-144$ & $132-136$ & $136-144$ & 1,00 \\
\hline DI8S53 & 11 & $165-173$ & $165-169$ & $169-173$ & 1,19 \\
\hline DI8S453 & 13 & $148-152$ & $152-152$ & $148-152$ & 2,13 \\
\hline DI8S7I & 13 & $270-278$ & $258-276$ & $258-278$ & 0,55 \\
\hline DI8S73 & 13 & $142-144$ & $142-146$ & $144-146$ & 1,98 \\
\hline DI8SIIO4 & 17 & |48-|52 & $|4|-\mid 48$ & $|4|-\mid 48$ & 1,10 \\
\hline DI8SII49 & 17 & $258-265$ & $263-267$ & $263-265$ & 0,77 \\
\hline DI8S869 & 18 & $186-198$ & $186-189$ & $186-198$ & 1,39 \\
\hline DI8S478 & 23 & $248-250$ & $246-246$ & $246-250$ & $|, 2|$ \\
\hline DI8SII02 & 33 & $90-94$ & $90-92$ & $90-94$ & 0,97 \\
\hline DI8S474 & 47 & $124-126$ & $132-138$ & $126-138$ & 2,68 \\
\hline DI8S6I & 66 & $228-230$ & $232-232$ & $228-232$ & 2,13 \\
\hline \multirow[t]{2}{*}{ DI8SII6I } & 70 & $231-233$ & $219-219$ & $219-233$ & 0,79 \\
\hline & & & & & Mean I,24 \\
\hline
\end{tabular}

The ratio between the maternal and paternal peak heights is given in the right column, with the geometrical means of each chromosome in bold. The names of the centromeric repeats are written in italics. 
from a skin biopsy taken from left groin, where skin pigment mosaicism could be seen. The reason for this, at least when the fibroblasts are concerned, can be the unpredictable distribution of mosaicism and not necessarily a negative selection process [10]. Even though we lack cytogenetic proof that the mosaicism affects other tissues than the bone marrow, the clinical picture suggests this. The child's phenotype has elements of resemblance to children with mosaicism for trisomy 8 or trisomy 18 (Table 2). In fact, there are no known physical features in the patient, with the possible exception of poorly developed lower eyelashes, that has not been reported in patients with trisomy 8 or 18 mosaicism [11-13].

This case is of particular interest because it illuminates early events in embryogenesis that may have implications for tumor biology. Our data suggests that all four chromatids of the homologous pair were pulled to one daughter cell only by the mitotic spindle apparatus, analogous to the syntelic attachment of the mitotic spindle that may be seen in tetraploid yeast cells [5]. Unlike other organisms, pairing of homologous chromosomes in somatic cells is commonly seen in Dipterians such as Drosophila and mosquitoes [14]. Notably, homologous pairing in both meiosis and mitosis occurs independently of synapsis and recombination [14]. Furthermore, the finding of (mosaic) segmental isodisomy as a disease mechanism in some cases of imprinting-related growth syndromes (e.g. Beckwith-Wiedemann syndrome and Russell-Silver syndrome,
[15]) also indicates that mitotic homologous pairing takes place. That such pairing is not limited to imprinted chromosomes are illustrated by the reports of children with recessive diseases due to homozygocity for mutations carried by one of the parents only, the disease manifesting due to segmental isodisomy formation [16-19].

We believe that the most likely explanation for the double tetrasomy is that the starting point was a tetraploid state, which is the normal situation after S-phase, or a tetraploid cell line. If the origin was a tetraploid state, aborted Sphase (mitotic slippage) or interrupted M-phase (failed cytokinesis) are possible mechanisms. Chromatid nondisjunction is one suggested reason for failed cytokinesis $[6,8]$. If the origin was a tetraploid cell line, there are scant indications that such cells may later become diploid. In Candida albicans tetraploid strains become diploid or near diploid through "concerted chromosome loss" [20]. In hepatic cells being tetraploid after fusion to bone marrow stem cells, a "reduction mitosis" appears to be able to transform tetraploid hybrids into diploids [21]. In both cases the mechanism is unknown. A variable number of tetraploid cells is commonly found in chorion villus or amniocyte cultures, but such cells are rarely found in liveborns [22]. The origin can be meiotic or mitotic errors $[23,24]$.

Conceivably, failed cytokinesis or mitotic slippage might be quite common events in early embryogenesis, for

Table 2: The patient's phenotypic features compared to cases with mosaic trisomy 8 or 18

\begin{tabular}{|c|c|c|}
\hline Our patient: Double tetrasomy $8+18$ mosaicism & $\begin{array}{l}\text { Trisomy } 8 \\
\text { mosaicism }\end{array}$ & $\begin{array}{l}\text { Trisomy } 18 \\
\text { mosaicism }\end{array}$ \\
\hline Short stature & & + \\
\hline Small head & + & + \\
\hline Feeding problems & & + \\
\hline Developmental delay & + & + \\
\hline Deafness, conductive & + & \\
\hline High frontal hairline/prominent forehead & + & + \\
\hline Low-set/posteriorly rotated ears & + & + \\
\hline Crumpled ear helices & & + \\
\hline Narrow/atretic auditory canals & + & \\
\hline Middle ear abnormalities & & + \\
\hline Short palpebral fissures & & + \\
\hline Epicantic folds & & + \\
\hline Downslant & + & \\
\hline Broad nasal bridge & + & + \\
\hline Thin upper lip & & + \\
\hline Small chin & + & + \\
\hline Short neck & + & + \\
\hline Skin pigmentation anomalies & + & \\
\hline Overriding toes & & + \\
\hline Coarctatio aortae & & + \\
\hline Ventricular septal defect (VSD) & + & + \\
\hline Persistent ductus arteriosus (PDA) & + & + \\
\hline Retinitis pigment.-like findings in retina & + & \\
\hline
\end{tabular}


Standard mitosis with chromatid non-disjunction

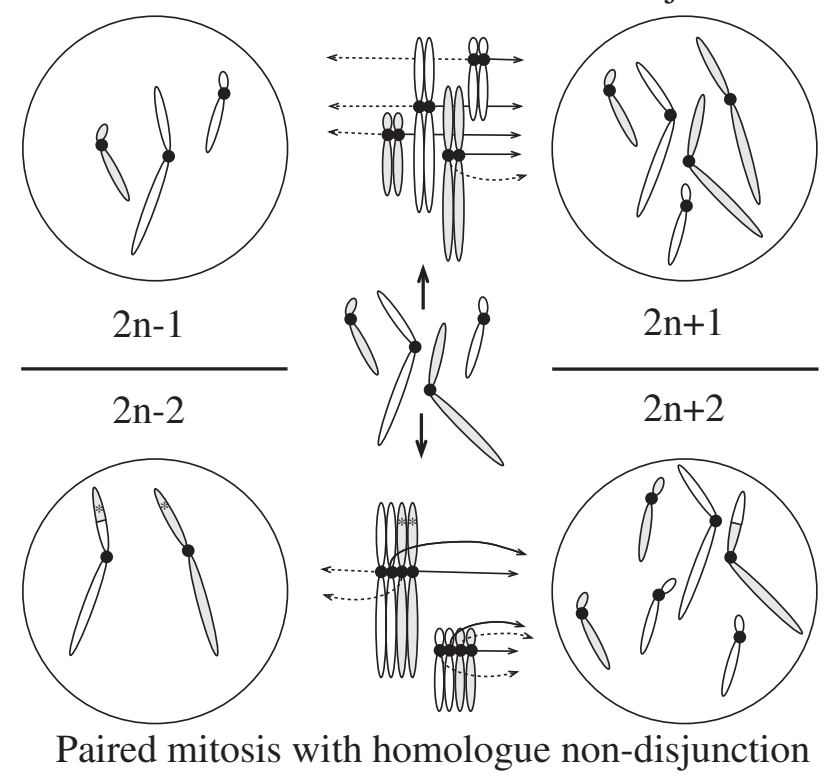

Figure 3

A drawing that exemplifies the hypothesized mitotic homologue non-disjunction. The upper part of the figure shows two separate homologue pairs from a conventional mitosis, and in one chromosome a chromatid non-disjunction occurs. The lower part of the figure illustrates two pairs of homologues from a mitosis where pairing has occurred between all homologue chromosomes, and where all (four) chromatids of one such pair segregates to the same daughter cell. We suggest that this might have happened very early in development to two homologue pairs, made by chromosomes 8 and 18 . We also illustrate how a detrimental mutation that has arisen during replication (marked by an asterix) may be eliminated by segregation to one daughter cell only after a mitotic cross-over that also generates a segmental (and terminal) uniparental isodisomy.

instance during the rapid cell cycles taking place in the peri-gastrulation stage of mammalian embryogenesis [25]. If there exists a special mechanism to deal with this, e.g. to reinitiate the spindle apparatus after the failure has been corrected, balanced segregation would be an advantage, and this could require pairing of the homologues. A further hypothetical advantage of such pairing is removal of replication errors or detrimental mutations from at least one of the daughter cells by segregating both chromatids of one homologous pair to the same daughter cell, if necessary after mitotic crossovers. In the latter case uniparental isodisomy (UPD) for the whole or a segment of a chromosome would be the result. Our hypothesis is illustrated in Figure 3, modeling single chromosome aneuploidy due to chromatid non-disjunction and double chromosome aneuploidy caused by paired homologues non-disjunction.

\section{Conclusion}

This unique case indirectly suggests that a mechanism for tetraploidy correction involving pairing of homologues may be present in somatic cells, and that mosaicism originating in tetraploidization could be a cause of developmental abnormalities that usually remain undetected. When such a mechanism is dysfunctional, aneuploidy is a likely result - which is commonly found in many types of cancer.

\section{Consent}

The parents have given written consent to publication of the patient's pictures, and the parents have also seen and approved the publication of the disease history.

\section{Competing interests}

The authors declare that they have no competing interests.

\section{Authors' contributions}

GH initiated the study, and was the person mainly responsible for its design and conclusions. HL carried out the molecular genetic studies and participated in the writing of the manuscript. SG collected clinical data and participated in the writing of the manuscript. All authors have read and approved the final manuscript.

\section{Acknowledgements}

The scientific discussion and review of the manuscript by Helge Boman and Anders Molven was highly appreciated. Noralv Breivik has provided additional clinical information. Most of the laboratory work has been done in the diagnostic DNA and cytogenetic laboratories at Haukeland University Hospital, lead by Hanne M. Jacobsen and Kjetil Solland. This work could not have been done without the collaboration of the child's parents, to whom we are most grateful.

\section{References}

I. Micale MA, Wolff DJ, Dickerman LH, Redline R, Conroy JM, Schwartz $\mathrm{S}$ : Cytogenetic and molecular genetic characterization of trisomy $\mathbf{2 0}$ mosaicism in fetal blood and tissues. Prenat Diagn 1996, 16(10):893-897.

2. Karadima G, Bugge M, Nicolaidis $P$, Vassilopoulos D, Avramopoulos D, Grigoriadou M, Albrecht B, Passarge E, Anneren G, Blennow E, et al: Origin of nondisjunction in trisomy 8 and trisomy 8 mosaicism. Eur J Hum Genet 1998, 6(5):432-438.

3. Callier P, Faivre L, Cusin V, Marle N, Thauvin-Robinet C, Sandre D Rousseau T, Sagot P, Lacombe E, Faber V, et al.: Microcephaly is not mandatory for the diagnosis of mosaic variegated aneuploidy syndrome. Am J Med Genet A 2005, I37(2):204-207.

4. Hanks S, Coleman K, Reid S, Plaja A, Firth H, Fitzpatrick D, Kidd A, Mehes K, Nash R, Robin N, et al.: Constitutional aneuploidy and cancer predisposition caused by biallelic mutations in BUB I B. Nat Genet 2004, 36(I I): I I59-I I6I.

5. Ganem NJ, Storchova Z, Pellman D: Tetraploidy, aneuploidy and cancer. Curr Opin Genet Dev 2007, 17(2): 157-I62.

6. Fujiwara T, Bandi M, Nitta M, Ivanova EV, Bronson RT, Pellman D: Cytokinesis failure generating tetraploids promotes tumorigenesis in p53-null cells. Nature 2005, 437(706 I): 1043-1047.

7. Weaver BA, Silk AD, Cleveland DW: Cell biology: nondisjunction, aneuploidy and tetraploidy. Nature 2006, 442(7104): E9-10. discussion EIO

8. Shi Q, King RW: Chromosome nondisjunction yields tetraploid rather than aneuploid cells in human cell lines. Nature 2005, 437(7061): 1038-1042. 
9. Lybaek H, Meza-Zepeda LA, Kresse SH, Hoysaeter T, Steen VM, Houge G: Array-CGH fine mapping of minor and cryptic HRCGH detected genomic imbalances in 80 out of 590 patients with abnormal development. Eur J Human Genet 2008, I6(II):1318-1328.

10. Houge G, Boman H, Lybaek H, Ness GO, Juliusson PB: Lack of meiotic crossovers during oogenesis in an apparent $45, X$ UIIrich-Turner syndrome patient with three children. Am J Med Genet A 2006, I40(10): 1092-1097.

II. Tucker ME, Garringer HJ, Weaver DD: Phenotypic spectrum of mosaic trisomy 18: two new patients, a literature review, and counseling issues. Am J Med Genet A 2007, I 43(5):505-5I7.

12. Su PH, Chen JY, Hsu CH, Chen SJ, Chan SW, Lin LL: Trisomy 18 with multiple rare malformations: report of one case. Acta Paediatr Taiwan 2007, 48(5):272-275.

13. Schinzel A: Catalogue of Unbalanced Chromosome Aberrations in Man. 2nd edition. Berlin; New York: Walter de Gruyter; 2001.

14. McKee BD: Homologous pairing and chromosome dynamics in meiosis and mitosis. Biochim Biophys Acta 2004, 1677(13): $165-180$.

15. Cooper WN, Curley R, Macdonald F, Maher ER: Mitotic recombination and uniparental disomy in Beckwith-Wiedemann syndrome. Genomics 2007, 89(5):6|3-617.

16. Kotzot D: Complex and Segmental Uniparental Disomy (UPD) Updated. J Med Genet 2008, 45(9):545-556.

17. Spiekerkoetter U, Eeds A, Yue Z, Haines J, Strauss AW, Summar M: Uniparental disomy of chromosome 2 resulting in lethal trifunctional protein deficiency due to homozygous alpha-subunit mutations. Hum Mutat 2002, 20(6):447-45I.

18. Chevalier-Porst F, Rolland MO, Cochat P, Bozon D: Maternal isodisomy of the telomeric end of chromosome 2 is responsible for a case of primary hyperoxaluria type I. Am J Med Genet $A$ 2005, I32A(I):80-83.

19. van Riesen AK, Antonicka $\mathrm{H}$, Ohlenbusch A, Shoubridge EA, Wilichowski EK: Maternal segmental disomy in Leigh syndrome with cytochrome c oxidase deficiency caused by homozygous SURFI mutation. Neuropediatrics 2006, 37(2):88-94.

20. Bennett RJ, Johnson AD: Completion of a parasexual cycle in Candida albicans by induced chromosome loss in tetraploid strains. Embo J 2003, 22(I0):2505-25I5.

21. Wang X, Willenbring H, Akkari Y, Torimaru Y, Foster M, Al-Dhalimy $M$, Lagasse E, Finegold M, Olson S, Grompe M: Cell fusion is the principal source of bone-marrow-derived hepatocytes. Nature 2003, 422(6934):897-90I.

22. Schluth C, Doray B, Girard-Lemaire F, Favre R, Flori J, Gasser B, Rudolf G, Flori E: Prenatal diagnosis of a true fetal tetraploidy in direct and cultured chorionic villi. Genet Couns 2004, I5(4):429-436.

23. Guc-Scekic M, Milasin J, Stevanovic M, Stojanov LJ, Djordjevic M: Tetraploidy in a 26-month-old girl (cytogenetic and molecular studies). Clin Genet 2002, 6 I (I):62-65.

24. Nakamura Y, Takaira M, Sato E, Kawano K, Miyoshi O, Niikawa N: A tetraploid liveborn neonate: cytogenetic and autopsy findings. Arch Pathol Lab Med 2003, I27(12):16|2-16|4.

25. O'Farrell PH, Stumpff J, Su TT: Embryonic cleavage cycles: how is a mouse like a fly? Curr Biol 2004, I 4(I):R35-45.

\section{Pre-publication history}

The pre-publication history for this paper can be accessed here:

http://www.biomedcentral.com/1471-2350/10/42/pre pub
Publish with Biomed Central and every scientist can read your work free of charge

"BioMed Central will be the most significant development for disseminating the results of biomedical research in our lifetime. "

Sir Paul Nurse, Cancer Research UK

Your research papers will be:

- available free of charge to the entire biomedical community

- peer reviewed and published immediately upon acceptance

- cited in PubMed and archived on PubMed Central

- yours - you keep the copyright
BioMedcentral 